\title{
Assessment of Tooth Metrics in Gender Determination-A Cross Sectional Study
}

\section{Introduction}

Gender determination is of prime importance in forensic investigations as it halves the number of possible matches [1]. Teeth are the hardest and most stable tissues in the body. Variations in size, appearance and stature of a particular object which can differentiate a male from female is referred to as sexual dimorphism. Odontometrics play an important role in assessing the gender of the individual, even before the secondary sexual characteristics are established. Teeth being the central component of masticatory apparatus, acts as an excellent tissue in genetic, odontologic, forensic and anthropological investigations. It is also resistant taphonomic degration compared to bone, which makes them a valuable tool in forensic identification and research. They are resistant to peri- and post-martem degradation, making them ideal for medico-legal investigation, such as in cases of mass fatalities where bodies have been damaged beyond recognition. Odontometric parameters such as mesiodistal and buccolingual dimensions have been shown to prove as accurate means for assessment of gender. Inter cuspal distances may also exhibit significant sexual dimorphism, compared to those obtained from conventional crown length and breadth dimensions [2]. The metrical approach to determining the gender is less subjective and more structured where repeated measurements can be taken to minimize error of the obtained results [1].

The existence of sexual dimorphism in canines and maxillary molars has been reported in the literature. However there is a void in the analysis of odontometrics in maxillary premolars. Hence this study intends to fill this void by determining the maxillary canine, maxillary first molar and maxillary first premolar odontometrics in establishing the dimorphic nature of Indian population.

\section{Materials and Methods}

\section{Patient sampling}

100 patients (48 male, 52 female) visiting Saveetha Dental College and Hospitals, Chennai, India, were chosen by random sampling method. With informed consent from the patient, alginate impression of the maxilla was made and set in type IV dental stone. The inclusion criteria included completely dentulous patients with no hard tissue anomalies. The criteria for exclusion were teeth with developmental anomalies, regressive changes, restorations, and patients with systemic illnesses.

\section{Assessment of tooth metrics}

The following measurements were made with the aerospace digital vernier caliper (Figure 1), rounded off to two places;

Mesiodistal diameter of the crown - the greatest dimension mesio-distally between the contact points; measured for the left and right canines, first premolars and first molars (Figure 2).

\section{Journal of}

Forensic Investigation

\section{Ashwini Shenai* and Nithya Jagannathan}

Department of Oral Pathology, Saveetha Dental College, 162, Poonamalee High Road, Thiruverkadu, Chennai-600077, India

\section{Address for Correspondence}

Ashwini Shenai, BDS Student, Department of Oral Pathology, Saveetha Dental College, 162, Poonamalee High Road, Thiruverkadu, Chennai-600077, India, E-mail: ashwini.shenai@gmail.com

Submission: 15 May, 2015

Accepted: 14 August, 2015

Published: 18 August, 2015

Copyright: ๑ 2015 Ashwini S, et al. This is an open access article distributed under the Creative Commons Attribution License, which permits unrestricted use, distribution, and reproduction in any medium, provided the original work is properly cited.

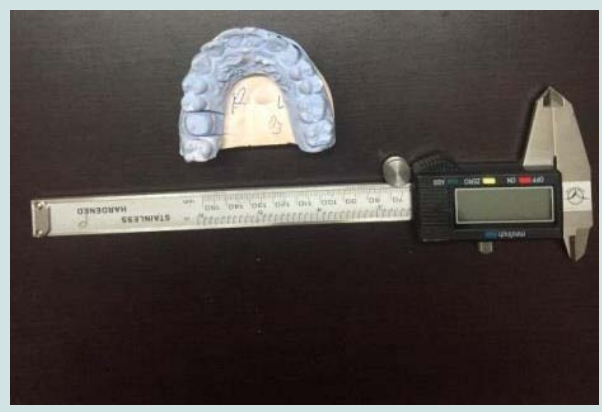

Figure 1: Aerospace digital vernier caliper.

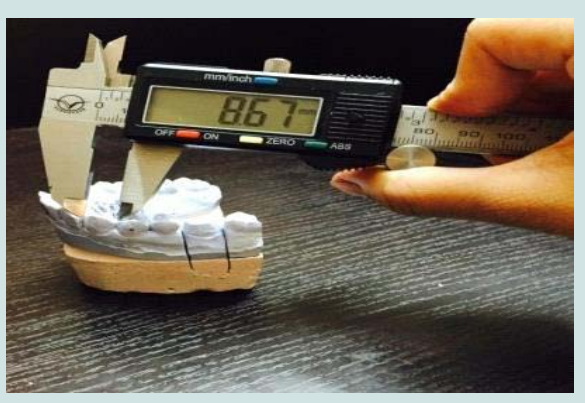

Figure 2: Measurement of mesiodistal diameter.

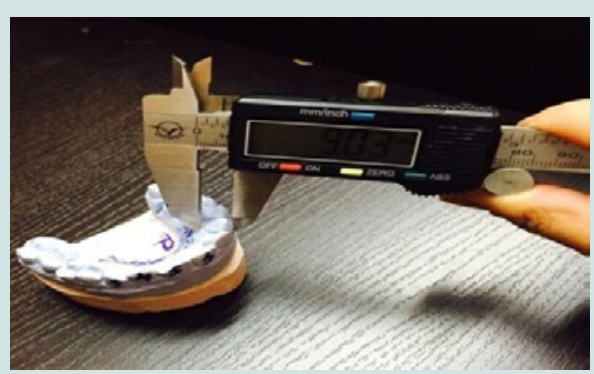

Figure 3: Measurement of buccolingual diameter. 


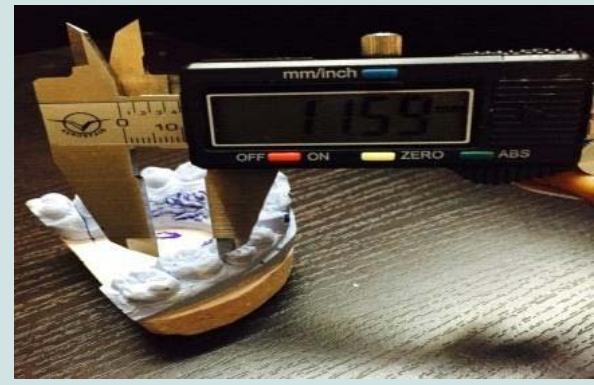

Figure 4: Measurement of intercuspal distances.
Buccolingual diameter of the crown- the greatest dimensions taken facio-lingually, perpendicular to mesiodistal dimension; measured for left and right canines, first premolars and first molars (Figure 3).

Intercuspal distances- mesiobuccal to distolingual and distobuccal to mesiolingual, measured for the left and right first molars (Figure 4).

The data was analyzed to find the mean and standard deviation of the odontometric parameters. Further tests of statistical significance such as unpaired t-test were undertaken.

Table 1: For left and right maxillary canines- $M D$ and $B L$ widths.

\begin{tabular}{|c|c|c|c|c|c|c|}
\hline Group & Gender & $\mathbf{N}$ & Mean & Std. Dev & t-Value & P-Value \\
\hline \multirow{2}{*}{ RIGHT CANINE BL WIDTH } & Male & 48 & 7.318 & 0.966 & \multirow{2}{*}{3.963} & \multirow{2}{*}{$<0.001$} \\
\hline & Female & 52 & 6.581 & 0.892 & & \\
\hline \multirow{2}{*}{ RIGHT CANINE MD WIDTH } & Male & 48 & 7.712 & 0.558 & \multirow{2}{*}{4.549} & \multirow{2}{*}{$<0.001$} \\
\hline & Female & 52 & 7.170 & 0.628 & & \\
\hline \multirow{2}{*}{ LEFT CANINE BL WIDTH } & Male & 48 & 7.310 & 0.964 & \multirow{2}{*}{4.622} & \multirow{2}{*}{$<0.001$} \\
\hline & Female & 52 & 6.463 & 0.869 & & \\
\hline LEFT CANINE MD WIDTH & Female & 52 & 7.098 & 0.672 & 5.150 & $<0.001$ \\
\hline
\end{tabular}

Table 2: For left and right maxillary molars- MD and $B L$ widths.

\begin{tabular}{|c|c|c|c|c|c|c|}
\hline Group & Gender & $\mathbf{N}$ & Mean & Std. Dev & t-Value & P-Value \\
\hline \multirow{2}{*}{ RIGHT MOLAR BL WIDTH } & Male & 48 & 10.881 & 0.738 & \multirow{2}{*}{4.708} & \multirow{2}{*}{$<0.001$} \\
\hline & Female & 52 & 10.161 & 0.788 & & \\
\hline \multirow{2}{*}{ RIGHT MOLAR MD WIDTH } & Male & 48 & 10.351 & 0.616 & \multirow{2}{*}{5.004} & \multirow{2}{*}{$<0.001$} \\
\hline & Female & 52 & 9.718 & 0.647 & & \\
\hline \multirow{2}{*}{ LEFT MOLAR BL WIDTH } & Male & 48 & 10.976 & 0.691 & \multirow{2}{*}{5.333} & \multirow{2}{*}{$<0.001$} \\
\hline & Female & 52 & 10.165 & 0.817 & & \\
\hline LEFT MOLAR MD WIDTH & Female & 52 & 9.659 & 0.625 & 5.623 & $<0.001$ \\
\hline
\end{tabular}

Table 3: For left and right maxillary molars: Intercuspal distances.

\begin{tabular}{|c|c|c|c|c|c|c|}
\hline Group & Gender & $\mathbf{N}$ & Mean & Std. Dev & t-Value & P-Value \\
\hline \multirow{2}{*}{ RIGHT MOLAR DB - ML } & Male & 48 & 11.443 & 1.002 & \multirow{2}{*}{5.016} & \multirow{2}{*}{$<0.001$} \\
\hline & Female & 52 & 10.504 & 0.870 & & \\
\hline \multirow{2}{*}{ RIGHT MOLAR MB - DL } & Male & 48 & 12.375 & 0.819 & \multirow{2}{*}{5.073} & \multirow{2}{*}{$<0.001$} \\
\hline & Female & 52 & 11.539 & 0.826 & & \\
\hline \multirow{2}{*}{ LEFT MOLAR DB - ML } & Male & 48 & 11.378 & 0.932 & \multirow{2}{*}{5.220} & \multirow{2}{*}{$<0.001$} \\
\hline & Female & 52 & 10.456 & 0.834 & & \\
\hline \multirow{2}{*}{ LEFT MOLAR MB - DL } & Male & 48 & 12.323 & 0.763 & \multirow{2}{*}{5.679} & \multirow{2}{*}{$<0.001$} \\
\hline & Female & 52 & 11.464 & 0.748 & & \\
\hline
\end{tabular}

Table 4: For left and right premolars- MD and BL widths.

\begin{tabular}{|c|c|c|c|c|c|c|}
\hline Group & Gender & $\mathbf{N}$ & Mean & Std. Dev & t-Value & P-Value \\
\hline \multirow{2}{*}{ RIGHT PREMOLAR BL WIDTH } & Male & 48 & 9.067 & 0.794 & \multirow{2}{*}{2.993} & \multirow{2}{*}{0.004} \\
\hline & Female & 52 & 8.619 & 0.703 & & \\
\hline RIGHT PREMOLAR MD & Male & 48 & 7.093 & 0.486 & \multirow{2}{*}{4.034} & \multirow{2}{*}{$<0.001$} \\
\hline WIDTH & Female & 52 & 6.661 & 0.576 & & \\
\hline \multirow{2}{*}{ LEFT PREMOLAR BL WIDTH } & Male & 48 & 9.004 & 0.734 & \multirow{2}{*}{2.757} & \multirow{2}{*}{0.007} \\
\hline & Female & 53 & 8.615 & 0.682 & & \\
\hline \multirow{2}{*}{ LEFT PREMOLAR MD WIDTH } & Male & 48 & 7.138 & 0.544 & \multirow{2}{*}{3.075} & \multirow{2}{*}{0.003} \\
\hline & Female & 53 & 6.786 & 0.601 & & \\
\hline
\end{tabular}




\section{Statistical analysis}

Results were tabulated and data analysed using SPSS software version 20.0. Independent samples T-test was used to compare mean values between genders.

\section{Results}

The 4 parameters - mesiodistal (MD) diameter, buccolingual (BL) diameter, mesiobuccal to distolingual (MB-DL) and distobuccal to mesiolingual (DB-ML) distances, were determined on the casts (Tables 1-4).

Mean and standard deviation were calculated for above parameters on all teeth. On comparing these values it was found that males had statistically higher values than females.

These results were further supplemented by tests of significanceunpaired $t$ tests where the two tailed $P$ value was less than 0.05 , which by conventional criteria, is extremely statistically significant.

\section{Discussion}

Significant difference in tooth metrics is observed between sexes. From forensic contexts, even few teeth recovered from the human dentition of 32 teeth could have a significant role in comparing human remains. Out of the many methods of gender discrimination such as DNA analysis and bone ossification test, odontometry is still widely preferred as it is reliable, easy and inexpensive [3].

In the present study, buccolingual and mesiodistal dimensions were measured. It was found that mean value for males was statistically higher than that of females for all teeth measured. This is in accordance to studies done by Iscan MY et al. whose study on 100 patients (50 male, 50 female), visiting Ankara University, Turkey showed that males exceeded females in terms of buccolingual dimensions [4]. A study conducted by Gloria staka, on 204 patients (101 male, 103 female), on the kosovo-albanian population showed that mesiodistal and buccolingual dimensions of maxillary canines were larger in males than females with highly statistical difference of less than 0.001 [5]. Eleni Zorba studied 133 patients of Greek population and found that mesiodistal and buccolingual dimensions of males significantly exceeded that of females with $p<0.05$ [6]. Ling JY's study on the southern chinese population consisting of 459 patient's states that male had larger mesiodistal dimensions in incisors, canines and premolars [7]. Suazo's study on the Chilean population of 150 patients concluded Chilean males had greater buccolingual dimensions on comparing canines and premolars [8]. A study on the Nepalese population by acharya [9] showed that buccolingual dimension maxillary molar showed significant statistically significant differences between sexes with males showing larger dimensions. Mohammed Nahidh's study on Iraqi population of 230 subjects showed greater mesiodistal dimensions in males with statistical difference of $<0.001$ [10].
The trend observed in the difference in values between the two genders could be due greater thickness of dentin in males as the $\mathrm{Y}$ chromosome induces dentinogenesis by increasing the mitotic potential of the tooth germ, whereas the $\mathrm{X}$ chromosome induces amelogenesis [11]. Larger jaw size in males could also be a contributing factor [12].

The present study on South Indian population visiting Saveetha Dental College, agrees with the above trends and concludes that mesiodistal and buccolingual dimensions of maxillary canines, premolars and molars in males is larger than that of females, with statistically significant value of less than 0.001 on performing independent value t-test.

\section{Conclusion}

This study has assessed tooth metrics in determination of gender in Indian population. Teeth are valuable sex indicators as they complete development before sexual maturation and can be used as odontometric standards [13].

\section{References}

1. Joseph AP, Harish RK, Rajeesh MP, Vinod Kumar R (2013) How reliable is sex differentiation from teeth measurements. Oral Max Path J 4: 289-292.

2. Macaluso PJ Jr (2010) Sex discrimination potential of permanent maxillary molar cusp diameters. J Forensic Odontostomatol 28: 22-31.

3. Işcan MY, Shihai D (1995) Sexual dimorphism in Chinese femur. Forensic Sci Int 74: 79-89.

4. Iscan MY, Kedici PS (2003) Sexual variation in bucco-lingual dimension in Turkish dentition. Forensic Sci Int 137: 160-164.

5. Staka G, Bimbashi V (2013) Sexual dimorphism in permanent maxillary canines. Int J Pharm Bio Sci 4: 927-932.

6. Zorba E, Moraitis K, Manolis SK (2011) Sexual dimorphism in permanent teeth of modern Greeks. Forensic Sci Int 210: 74-81.

7. Ling JY, Wong RW (2006) Tanaka-Johnston mixed dentition analysis for southern Chinese in Hong Kong. Angle Orthod 76: 632-636.

8. Suazo Galdames I, Cantín López M, López Farías B, Sandoval Marchant C, Torres Muñoz S, et al. (2008) Sexual dimorphism in mesiodistal and bucolingual tooth dimensions in Chilean people. Int J Morphol 26: 609-614.

9. Acharya A, Mainali $S$ (2007) Univariate sex dimorphism in the Nepalese dentition and the use of discriminant functions in gender assessment. Forensic Sci Int 173: 47-56.

10. Nahidh M (2014) The value of maxillary central incisors and canines in gender determination as an aid in forensic dentistry. Iraqi Den J 36: 8-12.

11. Vodanović M, Demo Ž, Njemirovskij V, Keros J, Brkić H (2007) Odontometrics: A useful method for sex determination in an archeological skeletal population J Arch Sci 34: 905-913.

12. Weston EM, Friday AE, Liò $P$ (2007) Biometric evidence that sexual selection has shaped the hominin face. PLoS One 2: e710.

13. Lund H, Mornstad H (1999) Gender determination by odontometrics in a Swedish population. J Forensic Odontostomatol 17: 30-34. 